\title{
Chlamydia pneumoniae IgG titres and coronary heart disease: prospective study and meta-analysis
}

\author{
John Danesh, Peter Whincup, Mary Walker, Lucy Lennon, Andrew Thomson, Paul Appleby,
} Yuk-ki Wong, Martine Bernardes-Silva, Michael Ward

\begin{tabular}{|c|}
\hline Editorial by Koenig \\
\hline $\begin{array}{l}\text { Clinical Trial } \\
\text { Service Unit and } \\
\text { Epidemiological } \\
\text { Studies Unit, } \\
\text { University of } \\
\text { Oxford, Oxford } \\
\text { OX2 6HE }\end{array}$ \\
\hline $\begin{array}{l}\text { John Danesh } \\
\text { clinical research fellow }\end{array}$ \\
\hline $\begin{array}{l}\text { Department of } \\
\text { Public Health } \\
\text { Sciences, St } \\
\text { George's Hospital } \\
\text { Medical School, } \\
\text { London } \\
\text { SW17 ORE }\end{array}$ \\
\hline $\begin{array}{l}\text { Peter Whincup } \\
\text { professor }\end{array}$ \\
\hline $\begin{array}{l}\text { Department of } \\
\text { Population Sciences } \\
\text { and Primary Care, } \\
\text { Royal Free and } \\
\text { University College } \\
\text { London Medical } \\
\text { School, London } \\
\text { NW3 2PF }\end{array}$ \\
\hline $\begin{array}{l}\text { Mary Walker } \\
\text { senior lecturer }\end{array}$ \\
\hline $\begin{array}{l}\text { Lucy Lennon } \\
\text { research assistant }\end{array}$ \\
\hline $\begin{array}{l}\text { Andrew Thomson } \\
\text { computer programmer }\end{array}$ \\
\hline $\begin{array}{l}\text { Imperial Cancer } \\
\text { Research Fund } \\
\text { Cancer } \\
\text { Epidemiology Unit, } \\
\text { Oxford OX2 6HE }\end{array}$ \\
\hline $\begin{array}{l}\text { Paul Appleby } \\
\text { statistician }\end{array}$ \\
\hline $\begin{array}{l}\text { Departments of } \\
\text { Cardiology and } \\
\text { Molecular } \\
\text { Microbiology, } \\
\text { University of } \\
\text { Southampton, } \\
\text { Southampton } \\
\text { SO16 6YD }\end{array}$ \\
\hline $\begin{array}{l}\text { Yuk-ki Wong } \\
\text { research registrar }\end{array}$ \\
\hline $\begin{array}{l}\text { Martine } \\
\text { Bernardes-Silva } \\
\text { research scientist }\end{array}$ \\
\hline $\begin{array}{l}\text { Michael Ward } \\
\text { professor }\end{array}$ \\
\hline $\begin{array}{l}\text { Correspondence to: } \\
\text { J Danesh }\end{array}$ \\
\hline
\end{tabular}

J Danesh

BMJ 2000;321:208-13

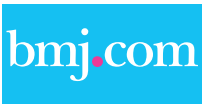

Further details of the meta-analysis are available on the BMJ's website

\begin{abstract}
Objective To examine the association between coronary heart disease and serum markers of chronic Chlamydia pneumoniae infection.

Design "Nested" case-control analysis in a prospective cohort study and an updated meta-analysis of previous relevant studies.

Setting General practices in 18 towns in Britain.

Participants Of the 5661 men aged 40-59 who provided blood samples during 1978-80, 496 men who died from coronary heart disease or had non-fatal myocardial infarction and 989 men who had not developed coronary heart disease by 1996 were included.
\end{abstract}

Main outcome measures IgG serum antibodies to $C$ pneumoniae in baseline samples; details of fatal and non-fatal coronary heart disease from medical records and death certificates.

Results 200 (40\%) of the 496 men with coronary heart disease were in the top third of $C$ pneumoniae titres compared with 329 (33\%) of the 989 controls. The corresponding odds ratio for coronary heart disease was $1.66(95 \%$ confidence interval 1.25 to 2.21), which fell to 1.22 ( 0.82 to 1.82 ) after adjustment for smoking and indicators of socioeconomic status. No strong associations were observed between $C$ pneumoniae IgG titres and blood lipid concentrations, blood pressure, or plasma homocysteine

concentration. In aggregate, the present study and 14 other prospective studies of $C$ pneumoniae IgG titres included 3169 cases, yielding a combined odds ratio of 1.15 ( 0.97 to 1.36$)$, with no significant

heterogeneity among the separate studies $\left(\chi^{2}=10.5\right.$, $\mathrm{df}=14 ; \mathrm{P}>0.1$ ).

Conclusion This study, together with a meta-analysis of previous prospective studies, reliably excludes the existence of any strong association between $C$ pneumoniae IgG titres and incident coronary heart disease. Further studies are required, however, to confirm or refute any modest association that may exist, particularly at younger ages.

\section{Introduction}

A study published in 1988 proposed that Chlamydia pneumoniae infection was an avoidable cause of coronary heart disease. ${ }^{1}$ Since then, systematic reviews have identified several dozen additional studies of $C$ pneumoniae markers and vascular disease. ${ }^{2-4}$ Although some reports have suggested twofold or larger odds ratios for coronary heart disease in people with markers of chronic $C$ pneumoniae infection, these studies have generally been small, retrospective, or liable to biases. ${ }^{2-4}$ We report a study of 496 cases of coronary heart disease and 989 controls "nested" in a prospective cohort of British men monitored for 16 years. We also conducted an updated meta-analysis of other prospective studies to place our results in context.

\section{Participants and methods}

\section{Cases and controls}

During 1978-80, 7735 men aged 40-59 (response rate $78 \%$ ) were randomly selected from general practice registers in each of 24 British towns and entered in the British Regional Heart Study. ${ }^{5}$ Nurses administered epidemiological questionnaires, made physical measurements, and recorded an electrocardiogram. Nonfasting venous blood samples were collected in 5661 men in 18 of the towns and stored at $-20^{\circ} \mathrm{C}$ for subsequent analysis. Further questionnaires were posted after five years (98\% response among survivors) and 12 years of follow up (90\% response among survivors) that asked about car ownership and childhood social circumstances (father's social class and childhood household amenities) respectively. All men have been monitored since entry for death from all causes and for cardiovascular morbidity, with a loss to follow up of less than $1 \%{ }^{5}$ Cases in our study were men who had fatal coronary events or non-fatal myocardial infarction between the beginning of follow up and December 1995 and who had a stored serum sample available for analysis. Fatal cases of coronary heart disease were ascertained through NHS central registers on the basis of a death certificate with International Classification of Disease (ICD-9) codes 410-414. Non-fatal myocardial infarction was based on reports from general practitioners, supplemented by evidence from general practice records, meeting World Health Organization criteria. $^{5}$ Of 507 potential cases (223 deaths from coronary heart disease and 284 non-fatal myocardial infarctions), 496 had $C$ pneumoniae measurements available. A total of 1026 controls, who were "frequency matched" to cases on town of residence and age in five year bands, were randomly selected from among men who had survived to the end of the study period without a myocardial infarction; 989 of these controls had C pneumoniae measurements available.

\section{Laboratory methods}

Laboratory workers unaware of the disease status of the participants analysed blood samples for $C$ pneumoniae using whole organism antigen and time resolved fluorimetry. ${ }^{6}$ The assay showed good agreement with microimmunofluorescence in a validation study of 480 people (intra-assay and interassay coefficients of variation were $4 \%$ and $8 \%$ ). Serum lipid concentration, albumin concentration, leucocyte count, and packed cell volume were measured with standard assays, and C reactive protein and serum amyloid A concentrations were determined by sensitive enzyme immunoassays. ${ }^{5}$ 


\section{Statistical methods and systematic review}

We compared case and control groups using unmatched stratified logistic regression fitted by unconditional maximum likelihood (Stata Corporation, College Station, Texas, USA). Adjusted analyses included the following explanatory variables: age; cigarette smoking habit (never, former, current); daily cigarette consumption; non-fasting blood concentrations of total cholesterol, high density lipoprotein cholesterol, and triglyceride; markers of current social class (registrar general's 1980 classification with a separate category for armed forces); housing tenure (owner, private rent, council rent); marital status; current car ownership; father's occupation (manual, non-manual); and childhood social circumstances (father's occupation, family car ownership, bathroom in house, hot water tap in house, bedroom sharing). We prespecified analysis of $C$ pneumoniae $\operatorname{IgG}$ titres by thirds of the values in controls - that is, the top third was defined as seropositive and the bottom third as seronegative. Previous systematic reviews suggested the need for adjustments for smoking and indicators of socioeconomic status in adulthood and childhood to help reduce any residual confounding in studies of coronary heart disease and persistent infective agents, and some previous studies of $C$ pneumoniae infection and coronary heart disease have reported adjustments for indicators of social class both in adult life and in childhood (see Discussion)..$^{2-5}$ We therefore prespecified that odds ratios would be reported both with and without such adjustments. For analyses of $C$ pneumoniae $\operatorname{IgG}$ titres with a variety of known and suspected risk factors, emphasis was given to differences greater than 2.6 standard deviations $(\mathrm{P} \approx 0.01)$ to make some allowance for multiple comparisons.

Methods to identify studies for an updated meta-analysis of prospective studies of coronary heart disease and $C$ pneumoniae $\operatorname{IgG}$ titres or IgA titres published before May 2000 have been described..$^{2}$ Cases were compared with controls only within the same studies to avoid potential biases (see BMTs website for full details).

\section{Results}

As would be expected, we found highly significant differences between cases and controls with respect to various known vascular risk factors such as smoking, obesity, blood pressure, and blood lipid concentration (table 1). C pneumoniae IgG titres were significantly associated with age and leucocyte count (table 2). Among cases, titres were also associated with smoking status, although this was attenuated by adjustment for indicators of socioeconomic status (data not shown). No significant associations were observed between $C$ pneumoniae IgG titres and various indicators of socioeconomic status and values of blood lipids, blood pressure, plasma homocysteine, $\mathrm{C}$ reactive protein, serum amyloid A protein, albumin, and packed cell volume.

Two hundred $(40 \%)$ of the 496 cases had serum IgG titres for $C$ pneumoniae in the top third compared with $329(33 \%)$ of 989 controls (table 3). This difference yielded an odds ratio for coronary heart disease of 1.66 (95\% confidence interval 1.25 to 2.21 ) in men in the top third of baseline $C$ pneumoniae IgG titres compared
Table 1 Baseline characteristics of men with coronary heart disease and of controls matched for age, sex, and town. Values are mean (SD) unless stated otherwise

\begin{tabular}{|c|c|c|c|}
\hline Characteristic & Cases $(n=507)$ & Controls $(n=1026)$ & $P$ value \\
\hline \multicolumn{4}{|l|}{ Questionnaire } \\
\hline Age (years) & $52.2(5.3)$ & $52.2(5.3)$ & Matched \\
\hline No (\%) of current smokers & $268(53)$ & $436(43)$ & $<0.0001$ \\
\hline No (\%) with evidence of coronary disease* & $177(35)$ & $204(20)$ & $<0.0001$ \\
\hline No (\%) with treated diabetes & $12(2)$ & $15(1)$ & NS \\
\hline No (\%) consuming >2 drinks alcohol/day & $110(22)$ & $232(23)$ & NS \\
\hline 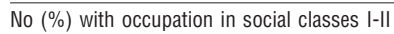 & $112(22)$ & $280(27)$ & 0.03 \\
\hline No (\%) of home owners $\dagger$ & $275(64)$ & $667(69)$ & 0.03 \\
\hline \multicolumn{4}{|l|}{ Physical measurements } \\
\hline Body mass index $\left(\mathrm{kg} / \mathrm{m}^{2}\right)$ & $25.8(3.4)$ & $25.3(3.3)$ & 0.008 \\
\hline Height $(\mathrm{cm})$ & $1.71(0.06)$ & $1.72(0.07)$ & 0.002 \\
\hline Weight (kg) & $76.3(11.4)$ & $75.8(11.2)$ & NS \\
\hline Systolic blood pressure $(\mathrm{mm} \mathrm{Hg})$ & $151(21)$ & $147(21)$ & $<0.0001$ \\
\hline Diastolic blood pressure $(\mathrm{mm} \mathrm{Hg})$ & 86 (14) & $83(13)$ & $<0.0001$ \\
\hline 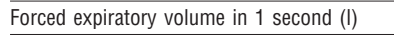 & $308(68)$ & $326(77)$ & $<0.0001$ \\
\hline \multicolumn{4}{|l|}{ Blood sample } \\
\hline Total cholesterol $(\mathrm{mmol} / \mathrm{l})$ & $6.63(1.10)$ & $6.20(0.99)$ & $<0.0001$ \\
\hline HDL cholesterol $(\mathrm{mmol} / \mathrm{l})$ & $1.10(0.28)$ & $1.15(0.29)$ & 0.0003 \\
\hline Triglyceride $(\mathrm{mmol} / \mathrm{l})$ & $2.26(1.33)$ & $1.93(1.22)$ & $<0.0001$ \\
\hline
\end{tabular}

*Evidence of ischaemia on baseline electrocardiogram or reported history of angina or myocardial infarction. †Information on home ownership was available for only 431 cases and 964 controls.

Table 2 Comparisons of levels of risk factors and other characteristics in controls by thirds of $C$ pneumoniae $\lg G$ titres. Values are means (SD) unless stated otherwise

\begin{tabular}{|c|c|c|c|c|c|}
\hline & $\begin{array}{c}\text { Top } \\
(\mathrm{n}=329)\end{array}$ & $\begin{array}{l}\text { Middle } \\
(\mathrm{n}=321)\end{array}$ & $\begin{array}{l}\text { Bottom } \\
(n=329)\end{array}$ & $t$ & \# \\
\hline Age (years) & $52.6(5.5)$ & $52.4(5.0)$ & $51.6(5.4)$ & 2.5 & $2.8^{*}$ \\
\hline No (\%) of current smokers & $160(49)$ & $131(40)$ & $131(40)$ & 1.4 & 1.8 \\
\hline No $(\%)$ consuming $>2$ alcohol drinks/day & $87(26)$ & $67(20)$ & $72(22)$ & 1.0 & 1.4 \\
\hline No (\%) with evidence of coronary heart & $66(20)$ & $61(18)$ & $67(20)$ & 0.4 & 0.9 \\
\hline
\end{tabular}

No (\%) with evidence of coronary heart

$66(20)$

$61(18)$

$67(20)$

disease at baseline

Physical measurements

Body mass index $\left(\mathrm{kg} / \mathrm{m}^{2}\right)$

Height $(\mathrm{cm})$

Weight $(\mathrm{kg})$

Systolic blood pressure $(\mathrm{mmHg})$

Diastolic blood pressure $(\mathrm{mmHg})$

\begin{tabular}{lrrrrr}
\hline Forced expiratory volume in 1 second (I) & $316(80)$ & $326(79)$ & $334(70)$ & 1.4 & 1.8
\end{tabular}

\section{Blood sample}

$\log _{10}$ C reactive protein $(\mathrm{mg} / \mathrm{l})$

$25.3(3.4) \quad 25.5(3.3) \quad 25.1(3.2) \quad 1.0 \quad 1.2$

$\begin{array}{lllll}172(7) & 173(7) & 174(6) & 1.5 & 1.5\end{array}$

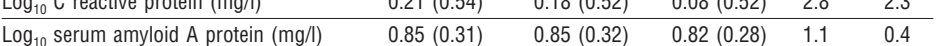

Albumin ( $\mathrm{g} / \mathrm{l})$

\begin{tabular}{llllll}
\hline White cell count $\left(\times 10^{9} / \mathrm{l}\right)$ & $7.3(1.7)$ & $7.3(1.8)$ & $7.1(1.8)$ & 2.9 & $3.3^{* *}$
\end{tabular}

\begin{tabular}{llllll}
\hline Total cholesterol $(\mathrm{mmol} / \mathrm{l})$ & $6.15(0.98)$ & $6.17(1.02)$ & $6.27(0.97)$ & 0.7 & 0.2 \\
\hline
\end{tabular}

\begin{tabular}{llllll}
\hline HDL cholesterol $(\mathrm{mmol} / \mathrm{l})$ & $1.17(0.32)$ & $1.13(0.27)$ & $1.17(0.27)$ & 0.5 & 0.0
\end{tabular}

\begin{tabular}{llllll}
\hline Triglyceride $(\mathrm{mmo} / \mathrm{l})$ & $1.85(1.10)$ & $1.98(1.12)$ & $1.94(1.27)$ & 1.0 & 0.6
\end{tabular}

\begin{tabular}{llllll}
\hline Homocysteine $(\mu \mathrm{mol} / \mathrm{l})$ & $15.2(10.1)$ & $15.1(9.8)$ & $14.6(7.6)$ & 0.1 & 0.1 \\
\hline Packed cell & $42.3(9.5)$ & $43.1(7.8)$ & $42.5(8.5)$ & 0.6 & 1.1
\end{tabular}

Packed cell volume (\%)

Socioeconomic factors§

No (\%) of subjects:

\begin{tabular}{lrrrrr}
\hline Non-manual occupation & $80(24)$ & $97(29)$ & $96(29)$ & 1.1 & 1.4 \\
\hline Homeowner & $211(68)$ & $215(70)$ & $215(69)$ & 0.1 & 0.2 \\
\hline Married & $297(90)$ & $284(86)$ & $291(88)$ & 0.0 & 0.0 \\
\hline Car owner & $227(73)$ & $236(77)$ & $248(79)$ & 1.2 & 1.0 \\
\hline Father with non-manual job & $193(80)$ & $188(74)$ & $189(73)$ & 0.5 & 0.4 \\
\hline Family owned a car & $26(10)$ & $39(14)$ & $45(17)$ & 0.6 & 0.7 \\
\hline Bathroom in house & $126(49)$ & $131(49)$ & $130(48)$ & 1.2 & 1.3 \\
\hline Hot water tap in house & $128(50)$ & $137(52)$ & $134(50)$ & 1.5 & 1.5 \\
\hline Bedroom shared & $172(67)$ & $179(67)$ & $167(62)$ & 0.1 & 0.2
\end{tabular}

${ }^{*} \mathrm{P}<0.01,{ }^{*} \mathrm{P}<0.001$.

$\dagger t$ tests derived from regression of $C$ pneumoniae $\lg G$ titres on each characteristic separately with adjustment for age and town only.

$\ddagger t$ tests derived from regression of $C$ pneumoniae $\lg G$ titres on each characteristic separately with adjustment for age, town, body mass index, and markers of socioeconomic status.

§Information on some factors available only in a subset of controls: car ownership 964, father's occupation 753 , family car ownership 789 , bathroom in house 791 , hot water supply 789 , bedroom sharing 790 , plasma homocysteine 416 . 
Table 3 Odds of coronary heart disease in men who were $\lg G$ seropositive for $C$ pneumoniae relative to those who were seronegative

\begin{tabular}{|c|c|c|c|c|c|c|}
\hline \multirow[b]{2}{*}{$\begin{array}{l}\text { Thirds of IgG titres in controls } \\
\left(\times 10^{6} \text { fluorescent count }\right)\end{array}$} & \multirow[b]{2}{*}{$\begin{array}{l}\text { No of } \\
\text { cases }\end{array}$} & \multirow[b]{2}{*}{$\begin{array}{l}\text { No of } \\
\text { controls }\end{array}$} & \multicolumn{4}{|c|}{ Odds ratio ( $95 \% \mathrm{Cl}$ ) with adjustments as indicated } \\
\hline & & & Age and town & $\begin{array}{l}\text { Age, town, and } \\
\text { smoking }\end{array}$ & $\begin{array}{c}\text { Age, town, smoking, } \\
\text { and adult } \\
\text { socioeconomic } \\
\text { status }^{\star}\end{array}$ & $\begin{array}{l}\text { Age, town, smoking, } \\
\text { and adult* and } \\
\text { childhood } \dagger \\
\text { socioeconomic status }\end{array}$ \\
\hline \multicolumn{7}{|l|}{ All 496 cases and 989 controls } \\
\hline Top third (>213) & 200 & 329 & $1.66(1.25$ to 2.21$)$ & 1.61 (1.21 to 2.15$)$ & 1.59 (1.17 to 2.16$)$ & $1.22(0.82$ to 1.82$)$ \\
\hline Middle third (166-213) & 169 & 331 & 1.38 (1.04 to 1.82$)$ & $1.36(1.03$ to 1.80$)$ & $1.36(1.00$ to 1.84$)$ & $1.06(0.72$ to 1.57$)$ \\
\hline Bottom third $(<166)$ & 127 & 329 & 1.0 & 1.0 & 1.0 & 1.0 \\
\hline \multicolumn{7}{|c|}{ Only those without evidence of coronary heart disease at baseline } \\
\hline Top third $(>213)$ & 116 & 262 & $1.34(0.95$ to 1.89$)$ & 1.31 (0.93 to 1.86$)$ & 1.30 (0.90 to 1.86$)$ & 0.98 (0.63 to 1.55$)$ \\
\hline Middle third (166-213) & 114 & 270 & $1.29(0.93$ to 1.80$)$ & $1.29(0.92$ to 1.80$)$ & $1.29(0.90$ to 1.83$)$ & 1.06 (0.68 to 1.63$)$ \\
\hline Bottom third $(<166)$ & 89 & 261 & 1.0 & 1.0 & 1.0 & 1.0 \\
\hline
\end{tabular}

Individuals with titres in the bottom third of the distribution in controls were regarded as seronegative.

${ }^{*}$ Smoking, occupation, housing tenure, marital status, car ownership.

†Father's social class, family car ownership, bathroom in house, hot water tap in house, bedroom sharing, height.

with men in the bottom third. The odds ratio was 1.59 (1.17 to 2.16) after adjustment for smoking and indicators of adult socioeconomic status and 1.22 (0.82 to 1.82) after additional adjustment for indicators of childhood socioeconomic status. These results were not materially changed when the analyses were adjusted for additional classic risk factors or when they were restricted to the 319 cases and 793 controls with no evidence of coronary heart disease at baseline (table 3 ) or to the 221 cases and 750 controls who had complete information on all reported markers of childhood socioeconomic status. Varying the cut-off titre did not materially alter the estimates.

\section{Discussion}

Previous retrospective serological studies have suggested that chronic $C$ pneumoniae infection is an important cause of coronary heart disease in the general population, ${ }^{1}$ but this hypothesis has not been adequately tested in larger prospective studies. In comparison with retrospective studies, prospective studies should reduce selection biases, minimise any influence of disease itself on the factor being investigated, and generally include better adjustment for potential confounding factors-for example, only about half of the retrospective studies of $C$ pneumoniae and coronary heart disease published before 1998 reported adjustment for cigarette smoking. ${ }^{23}$ Our prospective, community based study, with 16 years of mean follow up, included more coronary heart disease cases than all but one previous study. ${ }^{7}$ We found an odds ratio for coronary heart disease of 1.59 (1.17 to 2.16) in men with high baseline $C$ pneumoniae IgG titres after adjusting for smoking and markers of adult social class and an odds ratio of 1.22 (0.82 to 1.82) after additional adjustment for markers of childhood social class. The partially adjusted and fully adjusted odds ratios were statistically compatible with each other (because of relatively wide, overlapping confidence intervals) and were also compatible with either a moderately positive association or no association at all. We therefore conducted a systematic review of previous relevant studies of $C$ pneumoniae and coronary heart disease to assess further any association.

Meta-analysis

Including the present study, we identified 15 prospective studies of $C$ pneumoniae $\operatorname{IgG}$ titres and coronary heart disease up to May 2000.-20 The studies included a total of 3169 cases of non-fatal myocardial infarction or death from coronary heart disease; the weighted mean age at baseline was 56 years with a weighted mean follow up of 10 years. All adjusted for smoking and some other classic risk factors, but only seven (including our study) reported adjustment for markers of adult socioeconomic status ${ }^{7-12}$ and only two for markers of childhood social class. ${ }^{9}$ Ten of the studies used microimmunofluorescence assays (seven studies used $\geqslant 1: 64$ as a cut-off titre for seropositivity, ${ }^{81112151820}$ one study used $\geqslant 1: 128,{ }^{13}$ one used $\geqslant 1: 32,{ }^{17}$ and one did not specify the cut off ${ }^{16}$ ), and five used other methods (two used enzyme linked immunoassays, ${ }^{10}{ }^{19}$ two used time resolved fluorimetry, ${ }^{7}$ and one did not specify the exact method $^{14}$ ). Despite these differences, there was no significant heterogeneity among the 15 studies $\left(\chi^{2}=10.5, \mathrm{df}=14 ; \mathrm{P}>0.1\right)$, and a combined analysis yielded an odds ratio of 1.15 (95\% confidence interval 0.97 to1.36) for coronary heart disease (figure).

Subsidiary analyses yielded a combined odds ratio of 1.15 ( 0.84 to 1.57 ) in the eight studies (822 cases) that did not adjust for indicators of adult socioeconomic status ${ }^{13-20}$ and an odds ratio of 1.16 (0.95 to 1.41) in the 13 studies (2395 cases) that did not adjust for indicators of childhood socioeconomic status ${ }^{78}$ 10-20 Moreover, if the partially adjusted odds ratio for our study was used in the meta-analysis of all 15 studies (instead of the fully adjusted odds ratio), the combined odds ratio was still 1.19 (0.99 to 1.41). Similar results were obtained in the 10 studies (1521 cases) that used microimmunofluorescence assays (combined odds ratio 1.11 (0.87 to 1.42$)){ }^{8}{ }^{11-13}{ }^{15-20}$ and in the nine studies (1816 cases) that reported risk in relation to $C$ pneumoniae IgA titres (combined odds ratio of 1.13 (0.90 to 1.41)). ${ }^{7910131517-1921}$ Again, there was no significant heterogeneity among studies in any of these subsidiary analyses.

Our meta-analysis therefore reliably excludes any strong association between C pneumoniae IgG titres (or IgA titres) and coronary heart disease. Existing data are, however, insufficient to assess reliably any odds ratios weaker than about 1.5. Moreover, published studies have not corrected for possible underestimation due to fluctuations in serum antibody titres within individuals over time (as $C$ pneumoniae seropositivity may disappear and recur ${ }^{2}$ ). Further studies are therefore required to confirm or refute any more mod- 
Table 4 Some larger randomised trials currently in progress of antichlamydial strategies for prevention of coronary heart disease

\begin{tabular}{|c|c|c|c|c|c|}
\hline Study & Location & Planned size & Entry criteria & Drugs/duration (months) & Follow up (years) \\
\hline ACES* $^{*}$ & United States & 4000 & $\begin{array}{l}\text { Previous myocardial infarction or coronary } \\
\text { revascularisation }\end{array}$ & Azithromycin/12 & 4 \\
\hline PROVEIT* & United States & 4000 & Acute coronary syndrome & Gatifloxacin/18 & 1.5 \\
\hline WIZARD† & United States & 3800 & $\begin{array}{l}\text { Previous myocardial infarction or coronary } \\
\text { revascularisation }\end{array}$ & Azithromycin/3 & 3 \\
\hline MARBLE $^{*}$ & United Kingdom & 1300 & $\begin{array}{l}\text { Waiting for coronary artery bypass graft } \\
\text { surgery }\end{array}$ & Azithromycin/3 & 1 \\
\hline STAMINA* & United Kingdom & 600 & Previous myocardial infarction & $\begin{array}{l}\text { Azithromycin plus drugs against } \\
\text { Helicobacter pylori/0.5 }\end{array}$ & 1.5 \\
\hline
\end{tabular}

${ }^{*}$ Patients randomised irrespective of $C$ pneumoniae serostatus.

†Only patients with $C$ pneumoniae IgG titres $\geqslant 1: 16$ are to be randomised. In May 2000 WIZARD investigators announced possible enlargement of trial's sample size or longer follow up, or both, to increase its statistical power.

est association that may exist, particularly at younger ages, when associations may be stronger than at older ages. ${ }^{22}$

\section{Implications for randomised trials of antibiotic treatments}

Three randomised placebo controlled trials of antichlamydial treatments have reported on coronary heart disease events, ${ }^{2023-25}$ each including a few hundred patients with a history of coronary heart disease. All three trials put patients on brief courses of oral macrolides or macrolide derivatives (antibiotics with antichlamydial and, perhaps, anti-inflammatory effects). The first recorded only eight coronary events and yielded a non-significant result (although the investigators reported a fourfold reduction in coronary heart disease on the basis of an inappropriate non-randomised comparison). ${ }^{20}$ The second published trial recorded 22 events and also gave non-significant results after six months of follow up. ${ }^{23}$ Hence, in retrospect, this study's earlier claim of a fourfold reduction in coronary heart disease at one month was largely or wholly due to chance or selective reporting of an interim analysis. ${ }^{24}$ The third trial (also reported in an interim analysis) recorded 16 events and had non-significant results. ${ }^{25}$

Several trials are now in progress with larger sample sizes, lengthier antibiotic treatment periods, and more prolonged follow up (table 4). But even these trials may be able to provide only limited information about any effects of antichlamydial treatment in coronary heart disease. Our meta-analysis of prospective seroepidemiological studies creates considerable doubt about the existence of any independent association between persistent $C$ pneumoniae infection and coronary heart disease. The combined odds ratio was only 1.15 ( 0.97 to 1.36 ), which is much weaker than the combined weighted odds ratio for atherosclerosis of 20 (15 to 32) obtained from pathology based studies that have assessed human arterial specimens for endovascular markers of $C$ pneumoniae (DNA, antigens, elementary bodies, or viable organisms). ${ }^{2-4}$

What might account for this 20-fold discrepancy? Pathology based studies have been retrospective (thereby creating uncertainty about whether local $C$ pmeumoniae infection is a cause or consequence of atheroma), whereas the prospective serological studies assessed evidence of infection several years before the diagnosis of coronary heart disease. Most pathology based studies have also been prone to selection biases and lacked any adjustment for possible confounders such as age, sex, and smoking, ${ }^{2-4}$ but this could not plausibly explain much of the 20 -fold difference. It is also unclear to what extent the discrepancy can be accounted for by the different definitions of vascular disease (atheroma versus major coronary events) and the different markers of infection (endovascular markers such as DNA and antigens versus circulating antibody titres) used in these different sets of studies.

Such epidemiological uncertainties have implications for the numbers needed in clinical trials. If the 20 -fold odds ratio reported in the pathology based studies mainly reflected a causal effect that was largely reversible (rather than some artefact of confounding or reverse association), then antichlamydial treatments might be expected to reduce coronary event rates substantially. To confirm or refute such large effects should require trials only of similar size to the three previously reported trials (although, depending on the speed at which the risk reversed, follow up might need to be much longer). If, however, the prospective serological studies provide a more reliable guide to the likely strength of any association between $C$ pneumoniae and coronary heart disease, the trials would need to be much larger than those previously conducted or

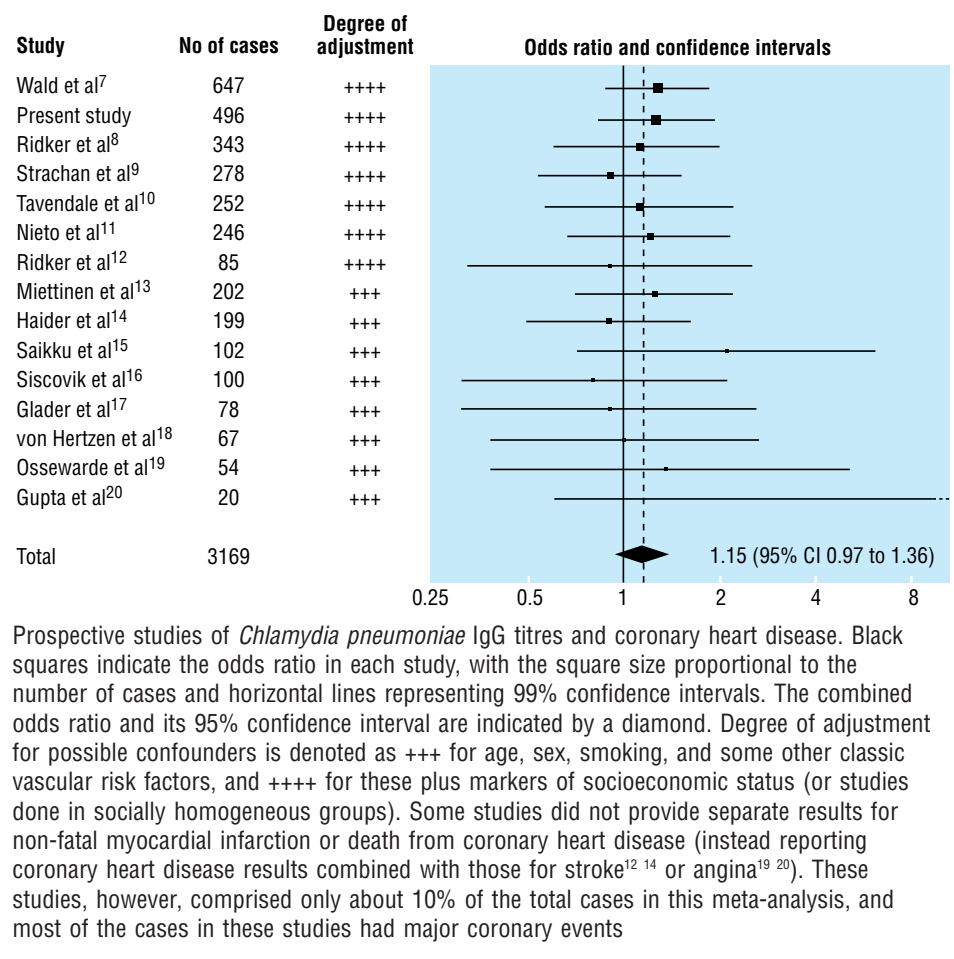




\section{What is already known on this topic}

Persistent infection with Chlamydia pneumoniae has been suggested to be an avoidable cause of coronary heart disease

Most previous studies on the topic have been small and prone to biases

\section{What this study adds}

Baseline $C$ pneumoniae IgG concentrations were not strongly associated with major coronary events or with classic or suspected risk factors

Updated meta-analysis of relevant prospective studies gave a combined odds ratio for heart disease of only about 1.1, which was not significant

Substantial uncertainty exists about any independent association between Chlamydia pneumoniae infection and heart disease

currently in progress. Even if there is a $10 \%$ excess risk due to $C$ pneumoniae that is fully reversible by antibiotics, none of the existing trials would be large enough to confirm or refute its existence (the largest current trials cannot detect reductions in coronary events that are less than $25 \%$; table 4 ).

\section{Conclusion}

Since 1997, the number of cases of coronary heart disease in prospective studies of $C$ pneumoniae IgG titres has increased 10-fold to over 3000 cases, with our study being one of the largest. Unlike previous retrospective studies, more reliable prospective data indicate that $C$ pneumoniae IgG titres are not strongly associated with coronary heart disease.

We thank H Refsum and P Ueland for the homocysteine assays; J R Gallimore and M B Pepys for the C reactive protein and serum amyloid A protein assays; J Atherton and C Hawkey for $H$ pylori assays; and J John for valuable help. Professor G Shaper established the British Regional Heart Study.

Contributors: The study was designed and conducted by the British Regional Heart Study collaborative group. All the named authors contributed to the analysis and interpretation of these data and to writing the paper. JD and PW are the guarantors.

Funding: The British Regional Heart Study is a British Heart Foundation research group and also receives support from the Department of Health. JD was supported by a Merton College fellowship and a Frohlich award.

Competing interests: None declared.

1 Saikku P, Leionen M, Mattila K, Ekman MR, Nieminen MS, Makele PH, et al. Serological evidence of an association of a novel chlamydia, TWAR, with chronic coronary heart disease and acute myocardial infarction. Lancet 1988;ii:983-6.

2 Danesh J, Collins R, Peto R. Chronic infections and coronary heart disease: is there a link? Lancet 1997;350:430-6.

3 Danesh J, Appleby P. Persistent infection and vascular disease: a systematic review. Expert Opin Invest Drugs 1998;7:691-713.

4 Wong YK, Gallagher PJ, Ward ME. Chlamydia pneumoniae and atherosclerosis. Heart 1999;81:232-8.

5 Whincup P, Danesh J, Walker M, Lennon, L, Thomson A, Appleby P, Atherton J. Prospective study of virulent strains of Helicobacter pylori and coronary heart disease. Circulation 2000;101:1647-52.

6 Wong Y-K, Sueur JM, Fall CHD, Orfila J, Ward ME. The species specificity of the microimmunofluorescence antibody test and comparisons with a time resolved fluoroscopic immunoassay for measuring antibodies against Chlamydia pneumoniae. J Clin Pathol 1999;2:99-103.

7 Wald NJ, Law MR, Morris JK, Zhou X, Wong Y, Ward ME. Chlamydia pneumoniae infection and mortality from ischaemic heart disease: results from a large prospective study. BMJ 2000;321:204-7.
8 Ridker PM, Kundsin RB, Stampfer MJ, Poulin S, Hennekens CH. Prospective study of Chlamydia pneumoniae IgG seropositivity and risks of future myocardial infarction. Circulation 1999;99:1161-4.

9 Strachan DP, Carrington D, Mendall MA, Ballam L, Morris J, Butland BK, et al. Relation of Chlamydia pneumoniae serology to mortality and incidence of ischaemic heart disease over 13 years in the Caerphilly prospective heart disease study. BMJ 1999;318:1035-40.

10 Tavendale R, Parratt D, Brook RA, Tunstall-Pedoe H. Antibodies to Chlamydia pneumoniae do not predict subsequent CHD in the Scottish Heart Health and MONICA studies [Abstract No P2221]. Eur Heart J 1999;20(suppl):450. (http://ex2.excerptamedica.com/99esc/)

11 Nieto FJ, Folsom A, Sorlie P, Grayston JT, Wang S, Chambless LE. Chlamydia pneumoniae infection and incident coronary heart disease: the Atherosclerosis Risk in Communities Study. Am J Epidemiol 1999:150:149-56

12 Ridker PM, Hennekens CH, Buring JE, Kundsin RB, Shih J. Baseline IgG antibody titers to Chlamydia pneumoniae, Helicobacter pylori, herpes simplex virus, and cytomegalovirus and the risk of future cardiovascular disease in women. Ann Intern Med 1999;131:573-7.

13 Miettinen H, Lehto S, Saikku P, Haffner SM, Rannemaa T, Pyorala K, et al. Association of Chlamydia pneumoniae and acute coronary heart disease events in non-insulin dependent diabetic and non-diabetic subjects in Finland. Eur Heart J 1996; 17:682-8.

14 Haider AW, Wilson PWF, Larson MG, Sutherland P, Evans JC, O'Donnell $\mathrm{CJ}$, et al. Chlamydia, $\mathrm{H}$ pylori and cytomegalovirus seropositivity and risk of cardiovascular disease: the Framingham heart study. J Am Coll Cardiol 1999;33(suppl A):314A.

15 Saikku P, Leinonen M, Tenkanen L, Linnanmaki E, Ekman MR, Manninen V, et al. Chronic Chlamydia pneumoniae infection as a risk factor for coronary heart disease in the Helsinki heart study. Ann Intern Med 1992;116:273-8

16 Siscovik DS, Schwartz SM, Grayston T, Tracy R, Kuller LH, Krommal RA. Antibody to Chlamydia pneumoniae, herpes simplex virus type 1 , cytomegalovirus and incident myocardial infarction and coronary heart disease death: the cardiovascular health study. Circulation 1997;97(suppl 1):814.

17 Glader CA, Boman J, Saikku P, Stenlund H, Weinehall L, Hallmanns, et al. The proatherogenic properties of lipoprotein(a) may be enhanced through the formation of circulating immune complexes containing Chlamydia pneumoniae-specific IgG antibodies. Eur Heart J 2000;21:639-46.

18 Von Hertzen L, Isoaho R, Kivela SL, Saikku P. Relation of C pneumoniae antibodies to ischaemic heart disease. BMJ 1999;1575-6.

19 Ossewaarde JM, Feskens EJ, De Vries A, Vallinge CE, Kromhout D. Chlamydia pneumoniae is a risk factor for coronary heart disease in symptom-free elderly men, but Helicobacter pylori and cytomegalovirus are not. Epidemiol Infect 1998;120:93-9.

20 Gupta S, Leatham EW, Carrington D, Mendall MA, Kaski JC, Camm AJ Elevated Chlamydia pneumoniae antibodies, cardiovascular events, and azithromycin in male survivors of myocardial infarction. Circulation 1997;96:404-7.

21 Roivainen M, Viik-Kajander M, Palosuo T, Toivanen P, Leinonen M, Saikku P, et al. Infections, inflammation and the risk of coronary heart disease. Circulation 2000;101:252-8.

22 Danesh J, Youngman L, Clark S, Parish S, Peto R, Collins R. Helicobacter pylori infection and early onset myocardial infarction: case-control and sibling pairs study. BMJ 1999;319:1157-62.

23 Gurfinkel E, Bozovich G, Beck E, Testa E, Livellara B, Mautner B. Treatment with the antibiotic roxithromycin in patients with acute non-Q-wave coronary syndromes: the final report of the ROXIS study. Eur Heart J 1999;20:121-7.

24 Gurfinkel E, Bozovich G, Daroca A, Beck A, Mautner B. Randomised trial of roxithromycin in non-Q-wave coronary syndromes: ROXIS pilot study. Lancet 1997;350:404-7.

25 Anderson JL, Muhlestein JB, Carlquist J, Allen A, Trehan S, Nielson C, et al. Randomized secondary prevention trial of azithromycin in patients with coronary artery disease and serological evidence for Chlamydia pneumoniae infection: the azithromycin in coronary artery disease: elimination of myocardial infection with chlamydia (ACADEMIC) study. Circulation 1999;99:1540-7.

(Accepted 6 June 2000)

\section{Endpiece}

I know him

You kill a man-that is easy ... it needs no skill. You can be certain of what you've done, you can judge death, but to save a man-that takes more than six years of training, and in the end you can never be quite sure it was you who saved him. Germs are killed by other germs. People just survive. There is not one patient whom I know for certain that I saved, but the man I killed-I know him.

Dr Hasselbacher in Our Man in Havana by Graham Greene, Penguin, 1962

Submitted by Alan P McGlennan, senior house officer in anaesthetics, Enfield 


\section{Commentary: Adjustment for potential confounders may have been taken too far}

\author{
Robert West
}

Danesh and colleagues' study, based on the 24 British towns study, shows a weaker association between markers for chronic or past infection with Chlamydia pneumoniae and incident ischaemic heart disease than some earlier reports. The odds ratio comparing highest with lowest tertiles of IgG titres was 1.7 and highly significant before adjustment. It remained highly significant (1.6) after adjustment for age, town, smoking, and social class but reduced to 1.2 and became non-significant after adjustment for childhood social class. The authors include this last estimate in their statistical overview of 15 prospective studies.

These findings provide an opportunity to review principles of adjustment (or standardisation) are essentially the same as those of matching when selecting controls in case control studies: to match for factors or characteristics known or previously shown to be causally associated with the disease. ${ }^{1}$ With the wisdom of hindsight, when chains of causality have been shown experimentally, it is not difficult to recognise and distinguish causal confounders, associated markers, and unrelated factors or characteristics, but identification is harder during analysis and interpretation of selecting controls and to overadjust in analysis.

A previous example, adjustment for birth weight in perinatal mortality, illustrates the point. We recommend adjustment for birth weight when comparing the performance of health authorities and hospitals (and doctors) so that like is compared with like and to compensate for the higher expected perinatal mortality in a hospital that admits more than its share of low birthweight babies. ${ }^{2}$ However, in a study of the aetiology of perinatal mortality it would be inappropriate to adjust for birth weight, since low birth weight (light for dates or premature delivery) could be an indicator of the same disease process as the perinatal mortality itself. $^{3}$ Adjusting for birth weight in an aetiological study of perinatal disease could be "throwing the baby out with the bathwater."

The analysis by Danesh and colleagues of the 24 towns study adjusts for both social class and childhood social class. Social class is a powerful epidemiological tool, and this United Kingdom measure is the envy of epidemiologists in many other countries. It is strongly associated with many diseases and is a useful proxy for exposure (occupational or environmental hazards, poverty, malnourishment, etc) and possibly for constitutional characteristics, but it is not a measure of exposure itself. Thus adjustment for social class, when we know little of the mechanism by which social class effects the disease under study, may be overadjustment.

In this study it is adjustment for childhood social class that removes the significance of the association (the "dose response," one of Bradford Hill's criteria for causality, although weakened, remains (see table 3)). In the 24 towns study childhood social class was estimated the rationale underlying adjustment in analysis. The observational studies. It is possible to overmatch when from a composite of measures, including bathroom in house. Like the adult classification, childhood social class is a potential proxy for many possible exposures, including nutrition and hygiene, or for various constitutional characteristics. It might be argued that poor hygiene and nutrition in childhood (low childhood social class) allows early infection by $C$ pneumoniae to become chronic, as indicated by raised IgG titres. It is perhaps appropriate to recall that, although tuberculosis was infectious among poorer people in urban slums, doctors and nurses in tuberculosis sanatoriums remained remarkably free of the disease. ${ }^{4}$ Associations between early antecedents, including childhood social class, and adult ischaemic heart disease are recognised, ${ }^{5}$ but there is poor understanding of the mechanisms by which childhood social class influences age at which ischaemic heart disease is manifest.

Until mechanisms are better understood, it seems wise to report associations without, as well as with, adjustment for childhood social class. Indeed, it could be argued that these associations should be summarised without, as well as with, adjustment for adult social class-if $C$ pneumoniae might be one mechanism by which social class affects age of onset of clinical heart disease. These reservations notwithstanding, the statistical overview does suggest that any association between markers of chronic infection by this organism and fatal or non-fatal myocardial infarction is not strong.

1 Rothman KJ. Modern epidemiology. Boston: Little Brown, 1986.

2 Chalmers I, Newcombe R, West RR, et al. Adjusted perinatal mortality rates in administrative areas of England and Wales. Health Trends 1978;10:24-9.

3 West RR. Perinatal and infant mortality in Wales: recent trends, interdistrict variations and associations with socio-environmental characteristics. Int J Epidemiol 1988;17:392-6.

4 Hart PD, Wright GP. Tuberculosis and social conditions in England. London: National Association for the Prevention of Tuberculosis, 1939.

5 Barker DJP, Osmond C, Winter PD, Margetts B, Simmonds SJ. Weight in infancy and death from ischaemic heart disease. Lancet 1989;ii:577-80.

\section{Endpiece}

Lord Moran on old age

Lord Moran, Churchill's doctor, who died in 1977 at the age of 94 , had this to say about old age and dying: "Old people with slow thoughts pass beyond the doubts and fears and hesitations of their middle years into the silence of great age, and when at last death comes to them quietly they hardly know their friendly visitor. Arteries harden, blanchening the seat of reason; men see life dimly as through a film, and find on the brink of dissolution that peace that passeth all understanding."

Moran C. The anatomy of courage. Boston: Houghton Mifflin, 1967

Submitted by Fred Charatan, retired geriatric physician, Florida

\author{
University of Wales \\ College of \\ Medicine, Cardiff \\ CF4 4XN \\ Robert West \\ reader in \\ epidemiology
}

